\title{
Emotional Intelligence and Academic Achievements of Upper Primary Rural Students in Relation to Their Gender, Family Type and Economic Class
}

\author{
Mukul Baran Mandal ${ }^{1}$ \\ ${ }^{I}$ Reseacrch Scholar, University of Burdwan, West Bengal, India
}

\begin{abstract}
The main objective of the present investigation was to study the emotional intelligence of upper primary rural students in relation to their gender (Boy-Girl), family type (Nuclear-Joint) and economic class (A.P.L- B.P.L). Sample of 200 rural students of age 14+ years studying in class $8^{\text {th }}$ standard were selected by stratified random sampling method from twenty rural upper primary schools. Bengali version $(r=.79, p<.01)$ of the Schutte Self Report Emotional Intelligence Test (SSEIT) was used for the study. F-tests, Students' t-tests and Correlation Coefficient were adopted to analyze the data for the study. The analysis yielded that there was no gender difference either in emotional intelligence or in academic achievements. Both emotional intelligence and academic achievements of the students of nuclear families were lesser than those of joint families. Again, it was observed from the analysis that the students belonging to Above Poverty Line (APL) scored higher in emotional intelligence as well as in academic achievements than the students Below Poverty Line (BPL). Finally, the analysis revealed that there existed a significant relationship between emotional intelligence and academic achievements of the rural upper primary students.
\end{abstract}

Keywords: Academic Achievements, A.P.L., B.P.L., Emotional Intelligence, Upper Primary Students

\section{Introduction}

In present education world one of the major objectives of school education is to place students in the certainty of successful academic achievement based on not only intelligence but also on other contributing factors such as emotional intelligence, social intelligence and luck factor (Goleman, 1995) ${ }^{[1]}$. Emotional intelligence represents the ability to understand, express and regulate emotions of self and others. Mayer \& Salovey, $\left(\mathbf{1 9 9 7}^{[2]}\right.$ defined emotional intelligence as "the ability to perceive emotions, to access and generate emotions so as to assist thought, to understand emotions and emotional knowledge, and to reflectively regulate emotions so as to promote emotional and intellectual growth".

According to Goleman (1995) ${ }^{[1]}$, there are five components of emotional intelligence. These are 1) Self -awareness that is knowing our emotions, 2) impulse control that is handling our emotions, 3) self-motivation that is motivating ourselves towards a goal, 4) empathy that is recognizing feelings of others and 5) relationship management that is to manage relationship to others in the society.

Academic achievement is viewed as the qualitative and quantitative aspect of students' work (Merriam Webster) According to Steinberger (1993) ${ }^{[3]}$, "Achievement encompasses student ability and performance; it is multidimensional; it is intricately related to human growth and cognitive, emotional, social, and physical development; it reflects the whole child; it is not related to a single instance, but occurs across time and levels, through a student's life in public school and on into post secondary years and working life."

A large body of literature has been documented the contribution of students' emotional intelligence to their academic performances. Some are reviewed here.

Bell (2008) ${ }^{[4]}$ conducted a study to examine the relationship between emotional intelligence and academic achievement in African American female college students. From the study it was found that emotional intelligence of those students was not significantly correlated with their academic achievements. But, stress management being one of the components of emotional intelligence, was weakly correlated with academic performances of the students.

Ogundokun and Adeyemo (Dec 2010) ${ }^{[5]}$ investigated the influence of emotional intelligence, age and academic motivation on academic achievement of the students at secondary level. They found emotional intelligence, age and academic motivation to be mildly correlated with academic achievement. They suggested that emotional intelligence should be accomplished in school curriculum by the curriculum developers and strong achievement motivation should be developed within the students through proper procedures so as to improve their academic performances.

Another study on Emotional Intelligence and Students' Academic Performances was undertaken by Adnan $\boldsymbol{e t}$ al. in $\mathbf{2 0 1 2}^{[6]}$. Nationality, age and gender were taken as factors for measuring the difference of 
emotional intelligence. The result indicated that emotional intelligence was positively correlated with the age of the students but uncorrelated with their academic performances, gender and nationality.

Bhadouria Preeti (May 2013) ${ }^{[7]}$ seek for the relationship between emotional intelligence and academic achievement, collecting the secondary data. He found out that the emotional intelligence was positively correlated with academic achievement. He also found that teaching emotional and social skills at school had an impact on short term as well as on long term academic successes.

Again in July $2013 \mathrm{~S}$ Chamundeswari ${ }^{[8]}$ made a study on emotional intelligence and academic achievement of higher secondary students. Their study revealed that the emotional intelligence was significantly correlated with academic achievements. The study also showed higher emotional intelligence and higher academic performances of the students of central board school in comparison to the students belonging to state board.

Chew et al. (March 2013) $\left.{ }^{[9}\right]$ made a cross sectional study on emotional intelligence and academic performance of medical students on the basis of multivariate analyses. They measured academic performance of medical students using continuous assessment (CA) and final examination (FE) results. The findings revealed that the medical students who were more emotionally intelligent performed better in both the continuous assessments and the final professional examination. They concluded that emotional skill development of medical students might enhance their academic performances.

Another cross-sectional study on medical students was done by Radfar et al. in $2013{ }^{\text {[10] }}$ to evaluate emotional intelligence and to establish its relationship with academic achievement of those students. They obtained a significant correlation between the scores of emotional intelligence and those of academic achievement. They also obtained academic achievement to be correlated with problem solving ability, stress tolerance and self-awareness too.

P Raj and V Chandramohan (2015) ${ }^{[11]}$ made a study on post graduate girl Psychology students to find out the relationship between emotional intelligence and the academic achievement. They showed that the students, who scored high in emotional intelligence, were academically excellent. Significant relationship existed between emotional intelligence and academic achievement of the students that is emotional intelligence played a major role in promoting academic achievement among college students.

Probha (2015) ${ }^{[12]}$ made a study to find out the relationship between emotional intelligence and academic achievement at higher education level. The investigator selected a sample of 310 first year degree students from various subjects and colleges both Government and private. She found that emotional intelligence was highly correlated with academic achievement, thereby implicating the need of emotional intelligence for promoting academic performances.

From the above reviews it appears that academic achievement is correlated with emotional intelligence. The present research examines whether emotional intelligence acts as a significant contributor of academic achievements of the upper primary school students in relation to their gender, family type and economic class.

\section{Objectives}

Following objectives were laid down for the present study.

i) To assess the emotional intelligence of upper primary students with the help of the Schutte Self Report Emotional Intelligence Test (SSREIT) in Bengali version

ii) To examine differences in relation to gender, family type and economic class in emotional intelligence as well as in academic achievements, of upper primary students

iii) To examine the degree of association between emotional intelligence and academic achievements of upper primary students

\subsection{Null Hypotheses}

The following null hypotheses were framed to achieve the above objectives.

1. $\mathrm{H}_{01}$ : Upper primary Boys and Girls do not differ significantly in relation to their emotional intelligence.

2. $\mathrm{H}_{02}$ : There is no significant difference between rural upper primary students belonging to Nuclear Families and those belonging to Joint Families in relation to their (students') emotional intelligence.

3. $\mathrm{H}_{03}$ : There is no significant difference between rural upper primary students who are Above Poverty Line (APL) and those who are Below Poverty Line (BPL), in relation to their emotional intelligence.

4. $\mathrm{H}_{04}$ : Upper primary Boys and girls do not differ significantly in relation to their academic achievements.

5. $\mathrm{H}_{05}$ : There is no significant difference between rural upper primary students belonging to Nuclear Families and those belonging to Joint Families, in relation to their (students') academic achievements.

6. $\mathrm{H}_{06}$ : There is no significant difference between rural upper primary students who are Above Poverty Line (APL) and those who are Below Poverty Line (BPL), in relation to their academic achievements.

7. $\mathrm{H}_{07}$ : Significant relationship does not exist between emotional intelligence and academic achievements, of rural upper primary students. 


\subsection{Variables}

a) Emotional Intelligence of upper primary students

b) Academic Achievements of upper primary students

c) Gender (Boy \& Girl ), Family Type (Nuclear \& Joint) and Economic Class (APL \& BPL)

\subsection{Research Method}

\section{Methodology}

Descriptive method was used for the purpose.

\subsection{Samples}

200 upper primary students, age 14+ years constituted the sample. Sampling was done by the method of stratified random sampling. Following is the categorical division of samples.

Table-1: Categorical Division of Sample

\begin{tabular}{|l|c|c|c|c|c|}
\hline \multirow{2}{*}{ Groups } & \multicolumn{2}{|c|}{ Nuclear } & \multicolumn{2}{c|}{ Joint } & \multirow{2}{*}{ Total } \\
\cline { 2 - 5 } & APL & BPL & APL & BPL & \\
\hline Boys & 25 & 25 & 25 & 25 & 100 \\
\hline Girls & 25 & 25 & 25 & 25 & 100 \\
\hline Total & 50 & 50 & 50 & 50 & 200 \\
\hline
\end{tabular}

\subsection{Research Tools}

i) Bengali version of Schutte Self Report Emotional Intelligence Test (SSREIT) (r-.79, p<.01) was used to measure the emotional intelligence of the upper primary students.

SSREIT( $\mathrm{r}=.90, \mathrm{p}<.01)$ in English Version was developed by Dr. Nicola Schutte in 1998. It has four dimensions namely, emotion perception, utilizing emotions, managing self- relevant emotions, and managing others' emotions. There are 33 items in SSREIT, which are to be answered in a five point scale $(1=$ strongly agree to $5=$ strongly disagree).

ii) Marks of annual Examinations of students (Class-VIII) were taken as their Academic Achievements.

\subsection{Procedure}

Firstly, twenty rural upper primary schools in Birbhum district were selected in purposive way. Then, from each school 20 boy students and 20 girl students of class VIII were randomly selected. Next, all the students were grouped into eight categories such as- APL Boys belonging to Nuclear Families, BPL Boys belonging to Nuclear Families, APL Girls belonging to Nuclear Families, BPL Girls belonging to Nuclear Families, APL Boys belonging to Joint Families, BPL Boys belonging to Joint Families, APL Girls belonging to Joint Families and BPL Girls belonging to Joint Families. Finally, from each group 25 students were randomly selected. Thus total sample became 200. Then all eight groups were complied and shorted as Boys (100) and Girls (100); again complied and shorted as APL (100) and BPL (100), similarly Nuclear (100) and Joint (100) groups were obtained. Thus, seven groups were formed namely, Boys, Girls, APL, BPL, Nuclear, Joint and Entire sample.

Then, Bengali version ( $\mathrm{r}=.79, \mathrm{p}<.01)$ of the Schutte Self Report Emotional Intelligence Test (SSEIT) was administered on those 200 students. And the total academic scores of last annual examination of the students were collected from the record books of schools.

The study followed inferential statistics. To test the null hypotheses $\mathbf{H}_{\mathbf{0 1}}$ to $\mathbf{H}_{\mathbf{0 6}}$, F-tests were adopted and then t-tests were followed where F-values were significant at .05 of lesser level. To test null hypothesis $\mathbf{H}_{\mathbf{0 7}}$ correlation coefficient was calculated.

\section{Data Analysis and Discussion}

4.1 Comparison of Scores in Emotional Intelligence with Respect to Gender, Class and Family Type

Table-1: $2 \times 2 \times 2$ ANOVA table Showing df, Sums of Squares (SS), Mean Squares (MS) and F-Values for Scores in Emotional Intelligence

\begin{tabular}{|l|c|c|c|c|}
\hline Source of Variance & df & SS & MS & F \\
\hline Due to Gender & 1 & 3.920 & 3.920 & $.024+$ \\
\hline Due to Family Type & 1 & 856.980 & 856.980 & $5.278^{* *}$ \\
\hline Due to Economic Class & 1 & 1290.320 & 1290.320 & $7.947^{*}$ \\
\hline Error & 192 & 31173.120 & 162.360 & \\
\hline
\end{tabular}

*Significant at .01 level, **Significant at .05 level, +Insignificant

Since F-value is not significant with respect to gender, t-test is not required. Therefore, the null hypothesis $\mathbf{H}_{\mathbf{0 1}}$ that is upper primary Boys and Girls do not differ significantly in relation to emotional intelligence is retained. 
Again, as the F-values are significant in respect of Family Type and Economic Class, t-tests are required to test whether there was any difference in Emotional Intelligence in respect of Family Type and Economic Class.

Table 2: Showing the t- Values along with Other Relevant Measures for the Scores in Emotional Intelligence

\begin{tabular}{|l|c|c|c|c|c|}
\hline Groups & $\mathrm{N}$ & Mean & $\mathrm{SD}$ & $\mathrm{SE}_{\mathrm{D}}$ & $\mathrm{t}$ \\
\hline Nuclear & \multirow{2}{*}{100} & 125.81 & 11.93 & 1.812 & $2.284 * *$ \\
\cline { 3 - 4 } Joint & & 129.95 & 13.64 & & \\
\cline { 1 - 3 } APL & \multirow{2}{*}{100} & 130.42 & 12.58 & 1.800 & $2.822 * *$ \\
\cline { 3 - 4 } & & 125.34 & 12.88 & & \\
\hline
\end{tabular}

**Significant at .05 level

Table-2 indicates that the t-value between students of Nuclear Families and those of Joint Families, in respect of emotional intelligence is found to be significant at .05 level. Therefore, the null hypothesis $\mathrm{H}_{02}$ that is, there is no significant difference between rural upper primary students belonging to Nuclear Families and those belonging to Joint Family in relation to their (students') emotional intelligence is rejected. Further, from the mean value it is inferred that rural upper primary students of Nuclear Families are less emotionally intelligent than those of Joint Families.

The reason behind this may be that the children of joint family are attached with more family members than the children of nuclear family are. As a result, they are influenced more by those family members as compared to the children belonging to nuclear families. Therefore, the scope of being developed of emotional intelligence in joint families is wider than those of in nuclear families and thus the children of joint families posses more emotional intelligence than the children of nuclear families.

Table-2 also shows the significant t-value between the emotional intelligence of APL and BPL students, thereby implying the rejection of null hypothesis $\mathrm{H}_{03}$ at .05 level. This means that there exists a significant difference between rural upper primary students who are (APL) and those who are (BPL) in relation to their emotional intelligence. From the mean values of the above table it can be stated that the difference goes in favor of APL students.

The explanation of this finding may be that the APL students belong to more cultured and educated families in comparison of BPL students. As education is one of the parameter of emotional intelligence, BPL families being less educated have less emotional intelligence and transmit less to their children. Moreover, family members of BPL students are rigorously engaged to bringing the breads, thereby getting little time for influencing on their children.

\subsection{Comparison of Scores in Academic Achievement with Respect to Gender, Class and Family Type}

Table-3: $2 \times 2 \times 2$ ANOVA table Showing df, Sums of Squares (SS), Mean Squares (MS) and F-Values for Scores in Academic Achievement

\begin{tabular}{|l|c|c|c|c|}
\hline Source of Variance & df & SS & MS & F \\
\hline Due to Gender & 1 & 3486.125 & 3486.125 & $1.702+$ \\
\hline Due to Family Type & 1 & 10614.245 & 10614.245 & $5.182^{* *}$ \\
\hline Due to Economic Class & 1 & 23263.245 & 23263.245 & $11.358^{*}$ \\
\hline Error & 192 & 393238.800 & 2048.119 & \\
\hline
\end{tabular}

*Significant at .01 level, **Significant at .05 level, +Insignificant

Since F-value 1.702 is not significant with respect to Gender, t-test is not performed. This implies that the null hypothesis $\mathbf{H}_{\mathbf{0 4}}$ that is upper primary Boys and Girls do not differ significantly in relation to their academic achievements is retained. That is, no gender difference appears in academic achievements. The reason behind this may be that as intelligence and attention do not depend on gender, the academic achievements do not vary within gender because intelligence and attention are two key factors of academic achievements.

It is also noted in table-3 that since F-values are significant with respect to Family Type and Economic Class, t-tests are required.

Table 4: Showing the t- Values along with Other Relevant Measures for the Scores in Academic Achievements

\begin{tabular}{|l|c|c|c|c|c|}
\hline Groups & $\mathrm{N}$ & $\mathrm{Mean}$ & $\mathrm{SD}$ & $\mathrm{S} . \mathrm{E}_{\mathrm{D}}$ & $\mathrm{t}$ \\
\hline Nuclear & \multirow{2}{*}{100} & 260.92 & 37.36 & \multirow{2}{*}{6.564} & $2.220^{* *}$ \\
\cline { 1 - 3 } Joint & 275.49 & 53.97 & & \\
\hline APL & \multirow{2}{*}{100} & 278.99 & 47.82 & \multirow{2}{*}{6.467} & $3.336^{*}$ \\
\cline { 1 - 3 } BPL & 257.42 & 43.53 & & \\
\hline
\end{tabular}

*Significant at .01 level, **Significant at .05 level 
Table-4 reflects the significant t-values between APL and BPL students as well as between the students of Nuclear Families and those of Joint Families in respect of their academic achievements. Therefore, we accept the null hypotheses $\mathbf{H}_{05}$ and $\mathbf{H}_{06}$ indicating that significant differences exist between rural upper primary students belonging to Nuclear Families and those belonging to Joint Families and between rural upper primary APL and BPL students, in relation to their academic achievements.

From the mean values in the above table it can be stated that the upper primary students of Nuclear Families are backward in academic achievements in comparison of the students of Joint Families where as rural upper primary APL students are advanced in academic achievements compared to BPL students of rural upper primary level. The reasons behind such findings are as follows.

The rural students of joint families are surrounded by many family members especially by the old ones and have the opportunities of getting assistance and being motivated to their studies. Therefore, the students belonging to Joint Families are advanced in educational progress than those belonging to Nuclear Families.

As BPL students get less monetary support than APL student, their (BPL students) study quality is poor (for lack of sufficient reference books, math kits, copies, etc.). Besides, most of BPL students have to assist their family members to their occupation. Hence, BPL students can manage little time for rendering to their study purpose both in schools and homes. For above two reasons, the BPL students' achievements in academy are poor in comparison of APL students.

Table.5: Showing the Value of Coefficient of Correlation(r) between Emotional Intelligence and Academic Achievements of Entire Sample

*Significant

\begin{tabular}{|c|c|c|}
\hline $\mathrm{N}$ & $\mathrm{r}$ & $\mathrm{p}$ \\
\hline 200 & $.543^{*}$ & .000 \\
\hline
\end{tabular}

Table-5 reflects the existence of significant correlation between emotional intelligence and academic achievements, of rural upper primary students, thereby rejecting the null hypothesis $\mathbf{H}_{\mathbf{0 7}}$. So, it can be stated that emotional intelligence and academic achievements, of rural upper primary students are significantly correlated. It implies that students' more achievements in academy help to enhance their emotional intelligence and vice versa.

\section{Conclusion}

Achievements in academy will be better when it is studying with more attention and applying more thinking power and consuming more time for this purpose. Therefore, students done better in academy can think more properly and can follow the behaviors of teachers, peers and family member with more attention. All these help them to flourish their emotional intelligence. Therefore, academic achievements should be correlated with emotional intelligence. This resembles with the finding of the present study which reveals a significant moderate relationship between emotional intelligence and academic achievements. On this basis of that relationship it can be concluded that students should be provided with more proper academic guidance, and should be motivated to study more and to do better in examinations. By doing so, their emotional intelligence will be promoted to the higher level.

On the contrary, it can also be stated that students' emotional intelligence should be developed by adopting some adequate techniques such as discussion, counseling, exposing to the outer world etc. so as to increase their understanding power, cogitation power and attention ability, thereby increasing the progress in academics. Therefore, the curriculum developers and educational planners should play the vital role in accomplishing emotional intelligence into the school curriculum to enhance the quantitative and qualitative aspects of students' works.

\section{References}

[1] D. Goleman, Emotional Intelligence, New Work: Bantam Books.

[2] J. D. Mayer \& P. Salovey, What is emotional intelligence? In P. Salovey \& D. Slueter (Eds.): Emotional development and emotional intelligence: implications for educators (pp. 3-31). New York: Basic Books, 1997.

[3] E. D. Steinberger, Improving student achievement. Virginia: American Association of School Administrators, 1993.

[4] B. F. Bell, Exploring the relationship between emotional intelligence and academic achievement in African American female college students, doctoral diss., College of notre dame of maryland, 2088.

[5] M. Ogundokun and D. Adeyemo, Emotional intelligence and academic achievement: The moderating influence of age, intrinsic and extrinsic motivation. The African Symposium, 10(2), 2010, 323-342.

[6] S Chamundeswari, Emotional Intelligence and Academic Achievement among Students at the Higher Secondary Level, International Journal of Academic Research in Economics and Management Sciences, 2 (4), 2013.

[7] A. Adnan, A. A. Chaudhry and M. I. Malik, Emotional Intelligence and Students' Academic Performance: A Study Conducted in Pakistan and Afghanistan, Science Series Data Report, 4(3), 2012, 61-69.

[8] B Preeti, Role of Emotional Intelligence for Academic Achievement for Students, Research Journal of Educational Sciences, 1(2), 2013, 8-12.

[9] Chew, et al, Emotional intelligence and academic performance in first and final year medical students: a cross-sectional study, BMC Medical Education, 2013. 
[10] S. Radfar et al, Evaluation of Emotional Intelligence and Its Relation to the Academic Achievement in Medical Students, Thrita, 2(2), 2013, 113-9.

[11] P. Raj, V. Chandramohan, Relationship between Emotional Intelligence and the Academic Achievement among College Students, The International Journal of Indian Psychology, 2(3), 2015.

[12] M. R. Prabha, Emotional intelligence as a correlate of academic achievement among first year degree students in Puducherry, India, International Journal of Current Research and Review, 3(6), 2015, 259-263. 